Kairos. Journal of Philosophy \& Science 22, 2019 Center for the Philosophy of Sciences of Lisbon University

\title{
The Gothic Uncanny: Selected Mind-Images in Literature and Film
}

Graça P. Corrêa Centro de Filosofia das Ciências, Faculdade de Ciências Universidade de Lisboa, 1749-016 Lisboa, Portugal CFCUL FCT UID/FIL/00678/2019 This research is supported by national funds through FCT- Foundation for Science and Technology, I.P. Portugal, under DL57/2016/CP1479/CT0074 gpcorrea@fc.ul.pt

DOI 10.2478/kjps-2019-0014

The concept of the uncanny has been a focus of critical, literary, and philosophical reflection since the nineteenth century. Two essays on the subject, both written in German in the early twentieth century, particularly stand out: the first by Ernst Jentsch, "On the Psychology of the Uncanny" (1906); the second by Sigmund Freud, "The Uncanny" (1919). Although distinct, these two reflections on the uncanny are admittedly inspired by a tale of Gothic fiction of the early nineteenth century written by E.T.A. Hoffmann and entitled "The Sandman" (1817). Whereas Jentsch sees the doll or womanlike automaton of the story (Olympia) as the most striking source of the uncanny due to the uncertainty or un-decidability of the inanimate/animate opposition (i.e., due to the doubt as to whether lifeless objects may or not be animate), Freud claims that the basis of the uncanny is the character of the sandman himself-a terrifying mythic figure who 
tears out children's eyes, an enforcer of castration, and thereby an eerie double of the protagonist's father.'

In both essays, Freud and Jentsch start by unpacking the word unheimlich (an adjective translating as frightening, eerie, sinister) in relation to its opposite, heimlich (denoting something intimate, friendly, familiar; but which may also be secretive, or kept from sight, such as the private parts of the human body). Apparently, the term heimlich already entails the idea of some kind of privacy or intimacy that is subject to concealment. Whereas unheimlich, according to philosopher Friedrich Schelling's earlier description, stands for something "which ought to have been kept concealed but which has nevertheless come to light". ${ }^{2}$ From this, Freud derives his own definition of the uncanny as "in reality nothing new or foreign, but something familiar and old-established in the mind:" some "secretly familiar" thing "which has undergone repression and then returned from it". ${ }^{3}$ For Freud, the uncanny is frightening because it reveals formerly concealed or suppressed aspects of others, and also of the self.

By making something familiar feel frighteningly unfamiliar, by revealing something un-homely at the heart of home, the uncanny is at the core of Gothic theory and aesthetics, especially because most of its fiction deals with the private or intimate sphere of family relations. As several Gothic scholars claim, the patriarchal family provides the organizing "myth" of the literature we call Gothic, ${ }^{4}$ for not only are certain features of the Oedipal structure consistently foregrounded in Gothic fiction, but it also manifests the dynamics of the patriarchal family as politics, as a "Law of the Father" that must be challenged and overturned. In other words, through uncanny effects, Gothic fiction reveals the ways in which patriarchal arrangements are "cultural" rather than biological or "natural".

In this article, I will specifically approach the Gothic uncanny of family relations as evoked in tales by E.T.A. Hoffmann and Edgar Allan Poe, and

1 See Freud, 1919, The Uncanny. The motif of the double is often found in Anglophone Gothic fiction, namely in Mathew Gregory Lewis's The Monk (1796), Edgar Allan Poe's William Wilson (1837), and Louis Stevenson's Doctor Jekyll and Mr. Hyde (1886), among many others.

2 Freud, 1919, 13.

3 Ibid., 12-13.

$4 \quad$ Williams, 1995, 29. 
in films by Alfred Hitchcock, David Lynch and Stanley Kubrick. Because Gothic fiction's tendency to render everyday objects and events disturbingly terrifying and strange has been predominantly investigated through Freudian psychoanalytic lenses, I will draw on schizoanalysis and the Deleuzian time-image to supplement and challenge existing psychoanalytic assessments of the uncanny.

As stated in my opening remarks, the concept of the uncanny has a history. This history "is inextricably bound up with the history of the Enlightenment and with European and North American Romanticism". ${ }^{5}$ As Mladen Dolar remarks, "In pre-modern societies the dimension of the uncanny was largely covered (and veiled) by the area of the sacred and untouchable. [But] with the triumph of the Enlightenment, (...) the uncanny became unplaceable; it became uncanny in the strict sense". ${ }^{6}$ Such a "movement from an age of faith to an almost entirely secular understanding of events," made all that was irrational, excessively emotional and phantasmagorical be relegated to the Gothic side of eighteenth-century culture, "uncannily" resurfacing in its fiction, performance and visual arts.

Indeed, Terry Castle argues that the uncanny is a function of the enlightenment, of an age not so much of reason, but also of paranoia, repression, and incipient madness-echoing what Foucault had already inferred in his study on Madness and Civilization. ${ }^{7}$ According to Castle,

the historic Enlightenment internalization of the spectral-the gradual reinterpretation of ghosts and apparitions as hallucinations, or projections of the mind-introduced a new uncanniness into human consciousness itself. The mind became a "world of phantoms" and thinking itself an act of ghost-seeing. ${ }^{8}$

Such a thesis demands that we link the uncanny to wider-ranging issues beyond the individual-psychological scope: it entails that we contextual-

\footnotetext{
$5 \quad$ Royle, 2003, 8.

6 Dolar, 1991, 7.

7 Castle, 1995, 6-8.

8 Ibid., 17.
} 
ize the concept historically and politically, and that we link the feeling of the uncanny to the study of the mind-brain, as I will clarify ahead.

Accordingly, although both Jentsch's and Freud's viewpoints on the uncanny may be relevant to this article's literary and film analysis, I will be adding a coexisting theoretical lens: that of schizoanalysis. As claimed by French philosophers Gilles Deleuze and Felix Guattari, "oedipality" is a culturally specific way of living desire, rather than a universal truth for all subjects at all times. Castration, doubleness and lack are not a primal condition, not inherent to desire, but instead an effect of historically grounded formations, of a conjoined economy of patriarchy and capitalism. A schizoanalytical perspective (in contrast to a psychoanalytical one) refutes the division of mental life into what is conscious and what is unconscious, the splitting of subject from object, the separation of inside from outside. As pre-individual, "Being is never One;" as individuated, it is still multiple, "multiphased," within a continuing process of "becoming". ${ }^{9}$

In psychoanalytical models of the subject, as Anna Powell remarks, the contents of the unconscious

remain fixed by significant family events from our early life. The time of psychoanalysis is the personal history of desire, taboo and repression. When the unconscious 'speaks' to us in displaced forms, its 'messages' may sometimes be uncanny, but they have an identifiable, deep structure that can be dredged up into the present and acknowledged. ${ }^{10}$

In schizoanalytic models, however, the individual is understood as undergoing a continuing process of individuation; she/he is seen as a desiring-machine that cannot be isolated from its surroundings or milieu, from social formations, or from all other individuals.

In this latter light, the Gothic uncanny offers potentially productive ways towards creative thinking. In contrast to a fantastic or marvelous

$9 \quad$ See Gilles Deleuze, 2004, "On Gilbert Simondon," in Desert Islands and Other Texts 1953-1974, 89: "Being is never One. As pre-individual, being is more than one-metastable, superposed, simultaneous with itself. As individuated, it is still multiple, because it is "multiphased," "a phase of becoming that will lead to new processes".

10 Anna Powell, 2007, 139. 
aesthetics, the Gothic mode requires realism in function or style (but not as a goal), so that "the laws of reality remain intact"." Due to this "realistic" depiction of preternatural events, the effect of the Gothic uncanny is particularly intensified: it generates a mind-numbing oscillation between two poles, opposing a reassuring inference on the nature of reality to an implausible deformation of the real. ${ }^{12}$ By producing "unlike" relations that do not enforce resemblance/likeness to what has been naturalized or is supposedly "real" (i.e., in contrast to psychic-physical illustrations or clichés); and by facilitating the perception that something that could not possibly happen is actually happening in a plane of consistency (where realism is not a goal but a function), it evolves into a "delirium" that catalyzes creative change, bringing about alternate perceptions of relations, and a renegotiation of difference and otherness in the world. ${ }^{13}$

\section{Edgar Allan Poe's The Fall of the House of Usher}

In his noteworthy book on the topic, Nicholas Royle argues that "the uncanny is not simply an experience of strangeness or alienation. More specifically, it is a peculiar commingling of the familiar and unfamiliar". ${ }^{14}$ Edgar Allan Poe's famous tale, The Fall of the House of Usher (1839), stands out as an early example of such an odd combination, due to its eerie effects set in a domestic environment. Poe's tale of insanity, premature burial, and a sentient house lies at the center of the Gothic tradition,

11 For more on the subject, see Tzevan Todorov, "The Uncanny and the Marvelous," a chapter of The Fantastic: A Structural Approach to a Literary Genre (1970).

12 Lloyd-Smith, 1989, 66.

13 In spite of the small number of direct references to the gothic in the work of Deleuze and Guattari, such as their intriguing comments on the "spirituality of the body" and "the gothic line in architecture," they make a broad use of examples from gothic fiction (by authors such as Lovecraft, Poe, and Kafka) in their philosophical works. See Anna Powell, "The Daemons of Unplumbed Space: Mixing the Planes in Hellboy," in Deleuze and Film, edited by David Martin-Jones and William Brown, Edinburgh University Press, 2012, 173-191, in which Powell observes that "Though brief, Deleuze's comments are suggestive, indicating his familiarity with and enjoyment of some gothic cinema" (186).

14 Royle, 2003, 1. 
and is perhaps "the most interpreted short story ever written, its ambiguities endlessly fascinating". ${ }^{15}$

Several critics consider that Poe's work supplied "language and a narrative structure to what Freud came to describe as the unconscious". ${ }^{16}$ Indeed, the Usher story may be read as a "metaphor of the self": be it of the mad narrator, an outsider who animates the ghostly residue in a mysterious manor; or of the estate's owner, the depressed and sickly Roderick Usher, final inheritor of a family history infused with traumas and terrifying secrets; or even of the imprisoned and repressed female of the house, Madeline Usher, who by collapsing over her brother causes the house to sink into the lake, leading to a renowned apocalyptic ending.

Beyond such psychological disintegration and revelation of "unconscious" hidden secrets, the uncanny of Poe's tale strikingly triggers social-political and world-historical resonances. According to Leslie Fiedler and Mark Edmundson, the work provides a glimpse into the dark nightmares of the American psyche, intensely conflicted by the constant play of fear and desire; or of American culture, deeply divided between the Gothic nightmare and the American Dream. ${ }^{17}$ In this sense, it is as if an idealized national "self" became undone by the return of its repressed Otherness.

Most significant, the uncanny in Poe's tale derives from his portrayal of haunting events set in a location that is inseparable from its inhabitants' mental states, and thus closely relates to Kubrick's The Shining, as some critics have asserted, and as I will clarify ahead. ${ }^{18}$ In effect, I suggest that Poe's uncanny stems from an animistic attitude of mind, from his Gothic-ecocentric perception of the liveliness of non-human materiality, which

15 Perry and Sederholm, 2009, 3. According to Perry and Sederholm, Poe is a most central figure of the American Gothic. The authors observe how Louis Gross's Redefining the American Gothic (1989) places Poe in a Gothic tradition, but not as a central figure; Teresa Goddu's Gothic America (1997) views Poe as a Gothicist; Poe is placed more centrally in Bloom's Gothic Horror (1998); but in Noël Carroll's The Philosophy of Horror (1990), Poe is just labeled a writer of terror.

16 Savoy, 2002, 181.

17 Ibid., 5-6.

18 In The Gothic Vision (2002), Dani Cavallaro writes: "Edgar Allan Poe's 'The Fall of the House of Usher' can be said to have generated a matrix for the exploration and portrayal of haunting situations as locations inseparable from their inhabitants' mental states" (87). 
was condemned by both Jentsch and Freud as "primitive" and disturbing. According to Freud, we all go through an animistic phase of individual and cultural development, which the sensation of the uncanny reactivates:

It would seem as though each one of us has been through a phase of individual development corresponding to that animistic stage in primitive men, that none of us has traversed it without preserving certain traces of it which can be re-activated, and that everything which now strikes us as "uncanny" fulfills the condition of stirring those vestiges of animistic mental activity within us and bringing them to expression. ${ }^{19}$

Likewise, according to Jentsch, such animism corresponds to a "natural tendency of man to infer, in a kind of naive analogy with his own animate state, that things in the external world are also animate or, perhaps more correctly, are animate in the same way". ${ }^{20}$

In Poe's "animistic" worldview, imagination can produce physical effects; all materiality is potentially changeable through the energy of one's thoughts, and therefore becomes "practically alarming". ${ }^{21}$ As Perry and Sederholm note, his characters "are haunted by powerful obsessions that, once combined with their equally strong imaginations, produce the very phantoms they fear the most". ${ }^{22}$ This is similar to what happens in E.T.A. Hoffmann's The Sandman, when the protagonist's bride, Clara, warns him that "the terrible things" which he speaks of merely occur "in his own mind:"

... we ourselves kindle the spirit, which we in our strange delusion believe to be speaking to us. It is the phantom of our own selves. (...) [But] if we have a mind that is suffi-

19 Freud, 1919, 13.

20 Jentsch, 1906, 12.

21 Briggs, 2015, 124.

22 Perry and Sederholm, 2009, 50. 
ciently firm, (...) then the dark power will fail in its attempt to gain a form that shall be a reflection of ourselves. ${ }^{23}$

It should be noted that Poe was acquainted with E.T.A. Hoffmann's short stories, some of them available in English translation, and reviewed by Walter Scott in a literary journal. ${ }^{24}$

Such "omnipotence of thoughts," which in both Poe's and Hoffmann's protagonists becomes a powerful source of uncanniness, is equally deemed by Freud as a vestige of an uncivilized intellect, revealing an animistic attitude of mind that endorses archaic beliefs, "at a time when our judgment has already rejected these same beliefs". ${ }^{25}$ By plunging its readers into a troubling uncertainty of what is real and unreal-of whether characters are concrete or else mere embodiments of the mind of other characters; of whether the house and surrounding nature are sentient or just reflections of an insane mind; of whether Madeline is buried alive or actually dead-Poe's tale corresponds to Jentsch's concept of the uncanny. According to Jentsch, however, such uncertainty reveals that humanity's intellectual mastery over their environment is not strong enough; it suggests that we have not yet won "that never-ending war between the human and the organic world for the sake of which the strongest and most impregnable bastions of science were erected". ${ }^{26}$ In contrast, Poe's use of the uncanny arises from his Gothic-Romantic opposition to the growing rationalism and scientificism that proceeded from the Enlightenment, and which are prevalent today.

Gilles Deleuze has elaborated a related critique of rationality when he argues that the rational is the way in which people pursue interests that have been defined within the confines of a society, and attempt to real-

23 Hoffmann, 2009, 154-8.

24 Perry and Sederholm, 2009, 9. Hoffman's tales were reviewed and published in the Foreign Quarterly Review (1827).

25 Freud, 1919, 12, note 17: "It would appear that we invest with a feeling of uncanniness those impressions which lend support to a belief in the omnipotence of thoughts, and to the animistic attitude of mind, at a time when our judgment has already rejected these same beliefs".

26 Jentsch, 1906, 16. 
ize them. ${ }^{27}$ Thus the exercise of their thought is in conformity with the aims of the real State-which "defines itself in principle as "the rational and reasonable organization of a community"'28_or with the dominant significations and requirements of the established order. According to Deleuze, therefore,

Reason is always a region carved out of the irrational - it is not sheltered from the irrational at all, but traversed by it and only defined by a particular kind of relationship among irrational factors. Underneath all reason lies delirium and drift. $^{29}$

What we call "reason" is but a certain ordering of desire, which does never exist in a free and unbound form, nor is it ever merely individual; rather, it is always arranged and assembled by a particular social formation.

Critics have suggested that Poe's tale of the sinking of a house together with its inhabitants may represent a dream that ends when the dreamer awakens. "Thus, the confusing relationships, contradictions, and impossibilities that the narrator describes perfectly embody the random way we remember dreams, with their lost narrative connections and character motivations". ${ }^{30}$ More to the point, however, the House of Usher is set in an uncanny place where reality and unreality have become blurred, where the categories of mind and world are confounded.

In his essay, Freud considers that the uncanny is precisely likely to arise "when the distinction between imagination and reality is effaced," when absolute discernment becomes impossible. ${ }^{31}$ Within the reorganization of normal perception that Deleuze and Guattari's schizoanalysis proposes, however, such undecidability between virtual and actual (dream and reality, past and present, true and false) is stimulating precisely because it endows the virtual with reality. Indeed, the power of the virtual is a mental reality, it "is a fundamentally characteristic of the schizophrenic delirium:

\footnotetext{
27 Deleuze, 2004, 262-3. My emphasis.

28 Deleuze, 1987, 375.

29 Deleuze, 2004, 262.

30 Perry and Sederholm, 2009, 53.

31 Freud, 1919, 15.
} 
even though it is not actual, it is very real". ${ }^{32}$ For the experience of uncertainty between virtual and actual relates the way of our own perceptions, thoughts, memories and desires.

\section{Hitchcock's Shadow of a Doubt}

Shadow of a Doubt (1943), ${ }^{33}$ the first film directed by Alfred Hitchcock set in America, was produced in the same period as Frank Capra's It's a Wonderful Life (1946); although both films are of a "comparable stature" and have as their common theme American small town and family values, they are aesthetically and politically different. ${ }^{34}$ In effect, I suggest that Hitchcock uses Gothic and film-noir imagery to uncannily expose the dark undercurrent below the façade of the happy American small-town family.

The uncanny of Shadow of a Doubt mainly derives from Hitchcock's use of doubles. Just as in Hoffmann's The Sandman the lawyer/optician Coppelius/Coppola and Nathaniel's father represent the two opposites of the father-imago, ${ }^{35}$ split into "one who threatens to blind him, that is, to castrate him, the other, the loving father, who intercedes for his sight," ${ }^{36}$ so do the two Charlies of Hitchcock's film-uncle Charlie and his young niece Charlie-represent bipolar opposites of experience and innocence; vice and virtue; obscurity and candor; darkness and light. Likewise, because young Charlie lives in Santa-Rosa and Uncle Charley lives in Newark, they provide a striking contrast between the "ordinary life" of small-town America, filled with "untroubled and peaceful stupid dreams," and the vicious life of the big-city, a decadent reality filled with nightmares. ${ }^{37}$

\footnotetext{
32 Pisters, 2008, 112.
}

33 The very title of Hitchcock's film is uncanny, since it derives from the expression "beyond or without a shadow of a doubt". If you know or believe something is beyond the shadow of a doubt, you are certain that it is true. Shadow of a doubt implies that it is doubtful.

34 See Robin Wood, Hitchcock's Films Revisited, Columbia University Press: New York, 1989.

35 Imago: term in Psychoanalysis that refers to an unconscious, idealized mental image of someone, especially a parent that influences a person's behavior. From OED online edition, 1989.

36 Freud, 1919, 7, note 8.

37 Spoto, 1999, 264. 
Hitchcock's film depicts the two Charlies as having an almost telepathic link, like lovers often do. As James McLaughlin observes, this uncanny "mental rapport" the pair of Charlies maintain often

extends into the physical, quite inappropriately: they often touch one another for too long (...). Even when Uncle Charlie grabs his niece violently ("You're hurting me!" she cries on two occasions), the camera angles suggest that the action could be part malevolent and part lusting, perhaps a peculiar fetish of the psychopathic uncle. ${ }^{38}$

This bonding between uncle and niece reaches its climax in what Paula Cohen names the "ring-giving" scene. ${ }^{39}$ The initial blocking of the actors, shying away from each other in the kitchen space, practically suggests the preliminaries of a declaration of love. The final offer and acceptance of the emerald ring, through a sequence that makes them approach their faces and touch each other's hands, both confirms and exalts their union: "We're not just an uncle and a niece. It's something else. (...) We're like twins," says young Charlie, "we both have secrets no one knows about". According to Freud, the uncanny "double" is originally an insurance against the destruction of the ego, and corresponds to a stage of primary narcissism. ${ }^{40}$ Correspondingly, young Charley's discovery of her autonomous adult self happens when she finds out that her uncle is a serial killer of widowed women.

From a psychoanalytical perspective, film critic Donald Spoto considers that Shadow of a Doubt's constant duality suggests, after all, that there are "two moral realities within a single family". ${ }^{11}$ Such is not Gilles Deleuze's understanding, however, when he writes that "in Hitchcock there is never duel or double". ${ }^{42}$ According to Deleuze's writings on film,

\footnotetext{
38 McLaughlin, 2009, 153.

39 Cohen, 1995, 72.

40 Freud, 1919, 9-10.

41 Spoto, 1999, 328.

42 Deleuze, 1986, 202.
} 
"Hitchcock introduces the mental image into the cinema," ${ }^{33}$ an image that takes as its object relations:

What matters is not who did the action - what Hitchcock calls with contempt the whodunit - but neither is the action in itself; it is the set of relations in which the action and the one who did it are caught. (...) There is not only the assassin and the victim, there is always a third and not an accidental or apparent third but a fundamental third constituted by the relation itself. (...) even in Shadow of a Doubt, the two Charlies, the uncle and the niece, both appeal to the same state of the world which, for the assassin justifies his crimes, and for the girl cannot be justified in producing such a criminal. ${ }^{44}$

If indeed it is the relation of "uncle-niece-social field" that is at stake in Shadow of a Doubt, we may infer that Hitchcock's film is tackling the micropolitics of desire of both Charlies within a matrix that is inseparable from both the libidinal and social-political economy in which they are immersed. In other words, what comes first between the uncle-niece double bonding is the social investment, the investment of the social formation, the oedipal economy in which they are trapped. Thus, as Robin Wood observes,

In Shadow of a Doubt, the family with its glow (its halo) may seem like a warm bath, but it all too readily becomes a swamp of frustrated yearnings, breeding demons of female emancipation whose ferocity it is barely able to contain. The representative American family, in short, is the true horror of the film. ${ }^{45}$

Thus, although in Capra's film the endorsement of family and smalltown values is "wonderfully" convincing, such a reaffirmation in Hitch-

\footnotetext{
43 Ibid., 200.

44 Ibid., 200, 202.

45 McLaughlin, 153.
} 
cock's film turns out to be "completely hollow". ${ }^{46}$ Indeed, as Deleuze claims, Hitchcock's films signal the crisis of the cinematic action-image and a transition towards the time-image, because what matters is no longer the action or the acting (the "whodunit"), but rather the set of relations in which the action and the one who did it are caught. Moreover, the uncanny in Shadow of a Doubt materializes through thought within the viewing process itself: the characters do not know of the set of relations they are engaged in, and it is the spectator who already knows or will discover before them. ${ }^{47}$

\section{David Lynch's Twin Peaks}

In Twin Peaks, ${ }^{48}$ David Lynch's "highly Gothic television series"49 produced in 1990, an uncanny proximity of "good" and "evil" is also shown to exist not only in the family home, but also at the heart of a small-town community. Lynch's exploration of the underside of American culture and fascination with repressed material evokes Hitchcock's own, which may well be due to a shared interest in the Gothic tales and poetry of Edgar Allan Poe. ${ }^{50}$ In Twin Peaks there are echoes of Poe in the recurrent incidence of grotesque figures, hideous metamorphoses, mutilated forms and figures: the brothel named "One-Eyed Jack's"; the one-eyed Nadine who uses an eye patch; the One-Armed Man who sells one-foot shoes, the repetitive one-eye shots of a raven's gaze. Parallel to the series' fixation with the staring eye or eyes, there is a fascination with extreme close-up shots of mouths, with frontier surfaces that lead inward toward the non-rational core of living beings.

46 Wood, 1989, 293.

47 Deleuze, 1986, 200-201.

48 The series comprises 29 episodes that aired on the $A B C$ network channel between April 1990 and May 1991. David Lynch co-authored and co-produced the entire series; and directed its first season.

49 Hogle, 2002, xxv.

50 Both directors refer to Poe's works as a source of inspiration for their films. Hitchcock stated that he tried to tell "unbelievable stories with a spellbinding logic" so that "you get the impression that the same thing could happen to you tomorrow" (Hitchcock, cited in Spoto, 39). According to Kenneth Kaleta, Lynch seems fascinated by the sensory experience of Poe's world "operating with an immediacy and intensity not of narrative development, but of the poetic concentration of images and sounds" (137). 
Echoing Poe, the contented robin of the title sequence-a familiar allusion to the tranquility of rural America-is negated by most of the images of non-human nature shown throughout the series, which are anything but peaceful. Outside, the woods are shadowy and threatening, populated by owls, ravens, and other birds of prey that seem to be vigilant of every human action. Inside, most rooms are filled with stuffed animals of different species-bears, foxes, birds and deer-hung on walls, standing on window sills and lying on tables. In the "Great Northern Hotel," hunting riffles hang over the beds like innocuous decorative objects, suggestive of a human culture that systematically suppresses, but is nevertheless haunted by, non-human Nature.

By combining various aesthetic genres-gothic mystery, noir thriller, social realism, soap melodrama and satire-Twin Peaks defies the traditional conventions of a television series and generates a feeling of uncanniness, or "a disturbing unfamiliarity in the evidently familiar". ${ }^{51}$ The series' Gothic aesthetic is evident in its atmospheric context, in the lyric depiction of death and non-human nature, and in the definitely gothic element of "the secret," which is structurally central to its plot. In effect, all the characters in Twin Peaks have something to hide: adulterous affairs, incestuous acts, perverse desires, criminal activities and troubled pasts; as a result, the action of the series is conducted by seeker-characters uncovering the schemes of secret-bearing figures.

Twin Peaks is filled with uncanny apparitions among familiar settings. Standing on the sidewalk, at the corner of the diner where Laura works as a waitress, appears the eerie Mrs. Tremont, a thin wrinkled lady who offers the young woman a framed picture of a semi-open door, or a passageway into her dreams. Standing next to Mrs. Tremont, and clinging to her hand, is her pensive grandson holding a featureless white plaster mask over his child's face. The uncannier scenes, however, are those set in the so-called "Red Room," a theatrical space with a checkered floor and enclosed on all sides by red drapes, where the characters dance and talk backwards.

51 See Lynch on Lynch, a series of interviews with David Lynch conducted by Chris Rodley between January 1993 and December 1996. 
Lynch considers that this room evokes the space of the subconscious, ${ }^{52} \mathrm{a}$ site of "non-rational energy in which all kinds of meaningful activity take place," a free zone of creative experiences, "completely unpredictable and therefore pretty exciting but also scary". ${ }^{53}$

Perhaps the uncanniest apparition in Twin Peaks is that of Killer Bob, ${ }^{54}$ a character who functions as the double of the town's attorney Leland Palmer, Laura's father and incestuous murderer. The latter is an attractive villain greatly esteemed by the small-town community, and a specialist who makes the rich richer through legal schemes that defer justice and enforce monopolies. According to Lynch, however, Killer Bob is not merely Leland's double, but also "an abstraction in human form," like a violent ghost of sexual viciousness that possesses various characters in the town of Twin Peaks, ${ }^{55}$ a reminder of a patriarchal culture where sex is but a tool of power, with women and children as its commoditized victims.

Laura Palmer's family home reflects the moral values of Twin Peaks' society. The living room decoration conforms to the ideals of domesticity: a carpeted space with tall windows dressed in light colored drapes, displaying the typical arrangement of a sofa in front of a TV set, with coffee tables and mantelshelves filled with happy-family portraits and sentimental bibelots. Whereas the ground floor is designated for public use and viewing, the upper floor is a realm of privacy. Often throughout the series, we are shown a low angle shot of the haunting stairway linking the two

52 Differently from the psychoanalytical notion of the unconscious (which consists of repressed material unacceptable to the conscious mind), the subconscious (the term in English was introduced by Thomas De Quincey in 1832) corresponds to emotional and extra-rational perceptions beneath normative awareness, but which may be accessed by one's consciousness.

53 Rodley, 1997, 19.

54 According to Lynch, in Lynch on Lynch, this character did not exist in the initial script, emerging by chance during the shooting of the pilot episode, when set dresser Frank Silva got himself accidentally locked up in the set of Laura Palmer's bedroom. As a result of seeing him look up furtively from behind Laura's bed, Lynch got the idea of creating Bob or "an abstraction with human form," and gave this part to Silva, who happened to be an actor (178).

55 The figures of authority in the town of Twin Peaks-a sheriff named Harry S. Truman (in an obvious allusion to the U.S. president who authorized the launching of the atom bomb), a senile mayor, a corrupt judge, an incestuous attorney, and a freaky psychiatrist (Dr. Jacobi) - all combine to compose the picture of a pathetic, but nevertheless menacing, all-male-dominated society. 
spaces (public and private), crowned by an incessantly rotating ceiling fan. According to Laura's mother, it was here that she saw her daughter alive for the last time: "She was going up the stairs... Those stairs".

The Palmer's stairway closely evokes a similar one figuring in the home of the Bates family, in Hitchcock's Psycho (1960). Likewise a site of mirrors and hideous secrets, Laura's room upstairs (which occupies the same position as the mother's room in Psycho) is constantly invaded by strange presences and rumors; and her only source of appeasement is a naïve picture of a cherubim presiding over a children's feast, like a deceptive illusion of love and security tragically trapped in a childish universe. In Twin Peaks, as in Psycho, home is a place haunted by childhood guilt, terrible repression, and family violence.

Like Hitchcock's Shadow of a Doubt, Twin Peaks is a story about smalltown America, about its apparently naïve way of life and underlying moral sickness. As Renée Tobe points out, Twin Peaks "takes the viewer on a willing pilgrimage across America" through various visual references that symbolize its "highest aspirations:" the small-town, the suburban house, the mall, the television set, the automobile, the truck trailer, the gas station, the diner, and the characteristic combination of coffee and doughnuts. ${ }^{56}$ Although set in the eighties, the series is filled with symbols of American popular culture from the 1950s, with "harmless" familiar features of an idealized post-WWII American culture that become uncanny and intimidating under the conservative political climate of Reagan's "moral majority" of the 1980s. As Lynch asserts, "[in the fifties] all the problems were there but it was somehow glossed over;" now that the gloss rots and breaks, a lot of slaughter and putrefaction come oozing out. $^{57}$

56 Tobe, 2003, 250.

57 In the director's own words, in Lynch on Lynch: "The fifties are still here. They're all around. They never went away. (...) The future was bright. Little did we know we were laying the groundwork then for a disastrous future. All the problems were there, but it was somehow glossed over. And then the gloss broke, or rotted, and it all came oozing out" (5). 


\section{Kubrick's The Shining}

Stanley Kubrick's The Shining (1980) ${ }^{58}$ has inspired much theorizing and deep analysis, perhaps more than any other major feature film during the last thirty-nine years. Additionally it has become a staple of popular horror film: the scene where the hotel's deranged caretaker, Jack Torrance (played by Jack Nicholson), smashes the bathroom's door with an ax, peers through a hole, and shouts to his wife: "Heeeere's Johnny!," is considered the scariest of all time in a scientific study made in $2013 .{ }^{59}$

The setting is an essential element of Kubrick's film: from the very beginning, as the camera follows the family car's journey across the immense and isolated mountainous region where the hotel is situated, we are made to feel the insignificance of human beings among a vast expanse of non-human nature. A huge mass overseeing the surrounding landscape, the Overlook Hotel displays a recreational hedge maze in front of its entrance, winding like a deadly trap. When taken inside the hotel, we enter yet another maze, equally unfriendly to humans: a sinister labyrinth of corridors carpeted with geometric bright-colored designs, endless rows of closed rooms, hallways with mirrors, a TV screen, a pair of ominous elevators, a lavish but empty ballroom, and further on a half-opened door leading to room 237.

Halfway through the film, Jack looks down upon a model of the Overlook's maze and perceives the minute figures of his wife and son moving about, extremely tiny and insignificant, matching Jack's stance at the very moment when he starts feeling the urge of murdering both of them. It is in this maze that Jack will be frozen to death by the film's end, with the ghastly facial expression of a monster. Thus, as in Poe's House of Usher, Kubrick's hotel seems to influence and shape the behavior of those who

58 The Shining was based on a novel by the same title by Stephen King.

59 Website Play.com polled 10,000 users to find the 10 films that most frightened customers, then used heart rate monitors to find out which scenes delivered the greatest chills. The most frightening scenes were calculated by identifying the percentage increases in film-goers' heart rates from spikes occurring at the same moments. The "Here's Johnny" scene made pulses jump by $28.2 \%$. See https://www.theguardian.com/film/2013/oct/31/ the-shining-heres-johnny-scariest-movie-scene-jack-nicholson. Accessed 18 December 2019. 
reside within its walls, suggesting that all materiality is sentient, alive, and has immanent effects. ${ }^{60}$

Similarly to Lynch's series, The Shining is filled with uncanny events and apparitions: there is an image of two elevators tossing heaps of fresh blood from their closed doors; the vision of two dressed-alike little girls, smilingly inviting Danny to "come play with us, forever... and ever... and ever," followed by a blunt shot of their bodies chopped to pieces; there is a close-up view of the demented text that Jack has been writing for weeks in his typewriter ("All work and no play make Jack a dull boy"); Jack's embrace of the attractive nude woman of room 237, who suddenly turns out to be dead (murdered long-ago in a bathtub) and decrepit (a mocking and laughing carcass, with decomposed skin falling apart); there is the famous "Redrum" word, written in lipstick by Danny during the film's climax, and which can only be understood through the mirror as spelling "murder" backwards; and finally, there is the dramatic concluding movement of the film, when the camera swoops inside the hotel's ballroom to locate Jack's face in a group picture of partying guests dated July 4, 1921.

In The Shining, the erosion between the real and the imaginary, so distinctive of Freud's definition of the uncanny, is obviously accompanied by doubles: the child Danny and his clairvoyant little finger "Tony," that warns him of things past, present and future (marking the gift of the shining); the little smiling twins; the pair of elevators; the Hotel's maze and its model; Jack and his double, Grady, the previous caretaker from ten years ago, who murdered his wife and daughters with an ax, and then killed himself. This doubleness is apparent not just in special patterns but also suggested through recurrent time loops-when Jack arrives at the hotel, he describes a sensation of familiarity and well-being, and reveals a feeling of déjà vu, that he has been there before; at the end of the film, we see him in a photograph taken in the 1920s, with a smiling and confident facial expression.

Similarly to three other works mentioned in this article-by Poe, Hitchcock and Lynch-the uncanny of Kubrick's film makes direct references

60 In Deleuze and Guattari's view of materiality, as exposed in A Thousand Plateaus, "it is not dead, insensitive, homogeneous matter, but a matter-movement bearing singularities or haecceities, qualities, and even operations" (512). 
to American culture and to the ghosts of its power ideologies. Due to its continual references to Native American history (such as that it was built "on an Indian burial ground"), 61 the Overlook hotel seems a container of historical suffering, an enduring manifestation of the racism and slaughter in American History. Additionally, the film's sufferers and murder targets are typically three of America's traditional victims: women (Wendy), children (Danny), and blacks (Halloran).

In this vein, Marxist critic Frederic Jameson considers The Shining to be a ghost story about the return of the historically repressed:

The Jack Nicholson of The Shining is possessed neither by evil as such nor by the "devil" or some analogous occult force, but rather simply by History, by the American past as it has left its sedimented traces in the corridors and dismembered suites of [the Overlook hotel]. ${ }^{62}$

The ghost story is contingent and dependent on physical place, on the material house as such, of which it is the bad dream; and, according to Jameson, "no building [is] more appropriate to express this than the grand hotel itself, with its successive seasons" of vacationers. Further, it is no wonder that the protagonist is haunted and possessed by visions set in the 1920s, since.

The twenties were the last moment in which a genuine American leisure class led an aggressive and ostentatious public existence, in which an American ruling class projected a class-conscious and unapologetic image of itself and enjoyed its privileges without guilt. ${ }^{63}$

61 References to Native American history abound in the film: 1) at the very beginning, when the family is driving to the hotel, Wendy brings up the Donner Party (an expedition to the West of the United States in 1846, of white pioneers who had to resort to cannibalism in order to survive) and an excited Jack talks about cannibalism with his son; 2) as the hotel manager explains when the family arrives, the hotel was built "on an Indian burial ground"; 3) the Overlook hotel is full of Indian artworks from "Navajo and Apache" tribes; 4) the date showing on the photograph at the end of the film is "July 4, 1921," corresponding to the anniversary of the discovery of America by the Europeans.

62 Jameson, $1981,8$.

63 Ibid., 8, 12. 
The nostalgia evoked by the film's protagonist expresses the desire for a vanished social hierarchy; Jack thus becomes the caretaker not just of the hotel, but also of the American dream itself.

Family relations are a central concern in The Shining. Significantly, Kubrick wrote the screenplay with Diane Johnson, a specialist in Gothic fiction, and they were particularly immersed in two texts while crafting it: in Bruno Bettelheim's The Uses of Enchantment (1976), and in Freud's essay on "The Uncanny". Hence, a psychoanalytic approach might apparently constitute a useful framework for interpreting the film. From a Freudian perspective, Christopher Hoile holds that the film presents us

... with a visible demonstration of the relation of the primitive animistic world to the ever-present Oedipal tensions between father, mother, and child. [...] The horror does not lie in the ghosts but in the inescapability of the Oedipal tensions in the family of which they are an expression. ${ }^{64}$

According to Hoile (via Freud), both Jack and his son Danny suffer from an animistic attitude of mind, from the belief that spirits inhabit all things, and that thoughts and wishes are all-powerful over physical reality. Further, (via Bettelheim), if animism is considered a natural and healthy stage of development for children, in the adult it signals a regression into primitivism.

In a contrasting non-Freudian Feminist view, Amy Nolan argues that Kubrick's film does not address the specific, personal story of the Torrance family, but instead interrogates the structure of the family system itself. According to Nolan, the emphasis of the film is

on the psychological breakdown of the American nuclear family in a culture that relies on hierarchies, progress as the "inevitable" destruction of nature, the rigidity of roles placed upon men and women, and the inherent devaluing of the latter. ${ }^{65}$

64 Hoile, 1984, 7.

65 Nolan, $2011,182$. 
In effect, the film often highlights both Jack's and his ghosts' notions/ delusions of masculinity, ${ }^{66}$ as deeply linked to a nostalgia of imperialist colonization, white supremacy, and patriarchal authoritarianism.

Within a different perspective of the film's uncanniness, in Cinema 2: The Time Image, Deleuze argues that the brain itself is the mise-en-scène of Kubrick's filmography: "the world itself is a brain, there is identity of brain and world, as in the Overlook Hotel in The Shining". ${ }^{67}$ In effect, "The gradual erosion of the frontier between the ego and the world, the real and imaginary, characteristic of schizophrenia, is visible in The Shining". ${ }^{68}$ We are led to feel that a continual compression of "objective" space (from the mountains to the hotel; from the hallways and lounges to specific chambers and decorative details), and of "objective" time (from months to days; from days to hours) is allied to an expansion of "inner" space and time-that not only affects Jack, but also Wendy and Danny, by contamination. The film thus seems to present a mind (or the sentient materiality of a brain) entering a delirium, and absorbing all contained or surrounding things and beings into that delirium. This mind is perhaps that of the Overlook hotel itself, as Greg Lambert suggests, "a traumatized brain and a psychotic interiority overdetermined by all the events of violence that have taken place in its own history". ${ }^{69}$

Most noticeably, I argue, the film's aesthetics and worldview are Gothic, for all its ghostly encounters between those who are living and those who are dead, or for the impossible presence of the past in the present, depicted in believable or realistic fashion. According to Kubrick himself, The Shining cannot be explained psychologically, for it actually unfolds "supernatural" events, ${ }^{70}$ as when the ghost of the former caretaker slides

66 Throughout the film, Jack's sense of self as well as the relationship with his wife and son are often influenced by his interactions with the ghosts of Lloyd (barman) and Grady (caretaker).

67 Deleuze, 2013, 205.

68 Ciment, 1982.

69 Lambert, 2008, 30.

70 The supernatural not in the sense of transcendent, for the Gothic mode implies an absence of religion, of a belief in God or in Evil, which would otherwise provide a conceivable cause for the uncanny, making it ineffective. See Kubrick on The Shining: An interview with Michel Ciment. 
open the bolt of the fridge storeroom, allowing Jack to escape and pursue his murdering chase. Although the director utilizes a realistic approach (which he equates with Kafka's style) to the characters, settings and lighting, he was interested in conveying psychic or extrasensory perception $(E S P)^{71}$ and the paranormal. For Kubrick, Danny's shining or ESP is real, although imperfect and fragmentary; the uncanny apparitions are "genuine," rather than mere projections of the characters' mental states; and so is Jack's reincarnation. The director concludes that this type of fiction obviously carries us "very quickly to the limits of knowledge and rational explanation". ${ }^{72}$

\section{Conclusion}

Stanley Kubrick states that he is "drawn precisely to the mechanisms of the uncanny and the double in order to reduce the exercise of reason in providing a measure of defense against the experience of uncertainty," since it is through the experience of uncertainty that we can closely relate to the reality of our own perceptions, memories, thoughts and desires. ${ }^{73}$ Kubrick's stimulating use of uncanny mechanisms seems to stand in complete contrast with the evaluation put forward by Freud and Jentsch, when both hold that animism, human ambiguity between life and death, and the belief in the omnipotence of thoughts - the very roots of the uncannycorrespond to a stage of individual infantile phantasy or to a primitive phase of human civilization as a whole, that must be (or has already been) surpassed.

In contrast to Freud and Jentsch's assessments, Deleuze also affirms the importance of uncertainty, or half uncertainty, in our neuronal transmission, as confirmed by the discovery of brain synapses, which definitely shattered the idea of a continuous cerebral system, or of the Brain as a

71 ESP or extrasensory perception is perception that occurs independently of sight, hearing, or other sensory processes. People who have extrasensory perception are said to be psychic. As Kubrick states in the above-mentioned interview: "I've always been interested in ESP and the paranormal. (...) I hope that ESP and related psychic phenomena will eventually find general scientific proof of their existence. There are certainly a fair number of scientists who are sufficiently impressed with the evidence to spend their time working in the field".

72 Kubrick on The Shining: An interview with Michel Ciment.

73 Lambert, 31. 
language and unified system. ${ }^{74}$ According to Deleuze, the cuts and breakflows allow the brain to be liberated "from the dominance of a too-structured brain, (...) from the readymade linkages, myths and clichés" of an unconscious produced under the regime of Oedipal economy. And it is here that the time-image of particular films is directly associated to the positive creation of a new image of the brain. ${ }^{75}$

Nonetheless, regarding the Gothic uncanny, it is helpful to avoid reinstating a binary opposition between psychoanalytic and schizoanalytic readings, and instead consider their complementarity: the first dealing with the trauma of the individual within the patriarchal family; the second investigating the libidinal economy of the social field, or the whole network of connections and desires in which individuals and families emerge. As Patricia Pisters observes, "Deleuze and Guattari do acknowledge the existence of Oedipal relations and have argued that they just want to break open the Oedipal theatre to add other dimensions," 76 so as to explore ways out of the psychoanalytic familial matrix.

To conclude, it is perhaps both fortunate and suggestive that the word uncanny in English is not synonymous with the German unheimlich. Derived from the seventeenth century Scottish "canny"-from "can" in the sense of "knowing"-uncanny becomes associated to unknowable. ${ }^{77}$ Such a dimension of the uncanny can be found all through the delirium of Hoffmann's, Poe's, Hitchcock's, Lynch's and Kubrick's fiction, which leads us back to the idea put forward by German Romantic thinkers such as Friedrich Schelling-whose definition of the uncanny was cited at the beginning of this article-that the work of art always points to its own incompleteness, while at the same time evokes what is beyond it: "art

$74 \quad$ Deleuze, 2013,318 , note 32.

75 Lambert, 2008, 28, 38.

76 Pisters, 2008, 109.

77 OED, 1989. Canny: origin 1637 (Scots), from can (in the obsolete sense 'know'). Uncanny: origin late 16th cent. (Scots) relating to the occult, malicious, from un [not] + canny. Can derives from Old English cunnan [know], related to Dutch kunnen and German können; from an Indo-European root shared by Latin gnoscere 'know' and Greek gignōskein 'know'. 
is the route to an understanding of what cannot appear as an object of knowledge". ${ }^{78}$

\section{Bibliography}

Botting, F., Townshend, D., (eds), 2004, Gothic: Critical Concepts in Literary and Cultural Studies, vol. 3. Routledge, New York.

Bowie, A., 2016, Friedrich Wilhelm Joseph von Schelling, The Stanford Encyclopedia of Philosophy (Edward N. Zalta, ed). Available at: https:// plato.stanford.edu/archives/fall2016/entries/schelling/. Accessed 18 December 2019.

Briggs, J., 2015, The Ghost Story. In: A new companion to the Gothic (David Punter, ed), John Wiley \& Sons, New York.

Castle, T., 1995, The female thermometer: eighteenth-century culture and the invention of the uncanny. Oxford University Press, New York.

Cavallaro, D., 2002, The Gothic Vision. Continuum, New York.

Ciment, M., 1982, Kubrick and the Fantastic. Available at: http://www. visual-memory.co.uk/amk/doc/0005.html. Accessed 18 December 2019.

Ciment, M., 1982, Kubrick on The Shining Interview. Available at: http://www.visual-memory.co.uk/amk/doc/interview.ts.html Accessed 18 December 2019.

Cohen, P.M., 1995, Alfred Hitchcock: The Legacy of Victorianism. University Press of Kentucky, Kentucky.

Deleuze, G., 2013, Cinema 2: The Time-Image. Translated by Hugh Tomlinson and Robert Galeta. Bloomsbury Academic, London/New York.

Deleuze, G., 2004, Desert Islands and Other Texts 1953-1974. Semiotextes, Paris.

Deleuze, G., 1986, Cinema 1: The Movement-Image. Translated by Hugh Tomlinson and Barbara Habberjam, University of Minnesota Press, Minneapolis.

$\overline{78 \text { Bowie, } 2016 .}$ 
Deleuze, G., Guattari, F., 1987 A Thousand Plateaus: Capitalism and Schizophrenia. Translated by Brian Massumi, University of Minnesota Press, Minneapolis.

Dolar, M., 1991, 'I Shall Be with You on Your Wedding-Night': Lacan and the Uncanny. October, 58, 5-23.

Freud, S., 1919, The Uncanny. Translated by Alix Stratchey. Available at: web.mit.edu/allanmc/www/freud 1.pdf. Accessed 18 December 2019.

Gross, L., 1989, Redefining the American Gothic. UMI Research Press, Michigan.

Hoffmann, E.T.A, 2009 (1816), The Sandman. Translated by John Oxenford. Digital Edition at: https://www.gutenberg.org/files/32046/32046h/32046-h.htm\#sandman. 18 December 2019.

Hogle, Jerrold, E., 2002 Cambridge Companion to Gothic Fiction. Cambridge University Press, Cambridge.

Hoile, C., 1984, The Uncanny and the Fairy Tale in Kubrick's The Shining. Literature/Film Quarterly 12, 1 , pp. 5-12.

Jameson, F., 1981, Historicism in The Shining. Available at: http://www. visual-memory.co.uk/amk/doc/0098.html. Accessed 18 December 2019.

Jentsch, E., 1906, On the psychology of the uncanny. Translated by Roy Sellars. In: Angelaki: Journal of the Theoretical Humanities 2.1 (1997). Available at: http://www.art3idea.psu.edu/locus/Jentsch_uncanny.pdf. Accessed 18 December 2019.

Hitchcock, A., 1943, Shadow of a Doubt, screenplay by Thornton Wilder, Alma Reville and Sally Benson, produced by Skirball Productions, Los Angeles.

Kaleta, K.C., 1993, David Lynch. Twayne Publishers, New York.

Kubrick, S., 1980, The Shining, screenplay by Stephen King and Diane Johnson, Warner Bros. Pictures, Los Angeles.

Lambert, G., 2008, Schizoanalysis and the Cinema of the Brain. In: Deleuze and the schizoanalysis of cinema, (Ian Buchanan and Patricia MacCormack; eds.), Continuum International Publishing Group, London.

Lloyd-Smith, A.G., 1986, Uncanny American fiction: Medusa's face. St Martin's Press, New York. 
Lynch, D., 1989, Twin Peaks, produced by Lynch-Frost Productions/ Spelling Entertainment/Propaganda Films, Los Angeles.

McLaughlin, J.B., 2009, All in the Family: Alfred Hitchcock's Shadow of a Doubt. In: A Hitchcock Reader (Marshall Deutelbaum and Leland A. Poague, eds.), $2^{\text {nd }}$ edition, Wiley-Blackwell, London.

Nolan, A., 2011 , Seeing is Digesting: Labyrinths of Historical Ruin in Stanley Kubrick's The Shining. Cultural Critique, 77, pp. 182-204.

Perry, D.R, Sederholm, C.H., 2009, "The House of Usher" and The American Gothic. Palgrave Macmillan, New York.

Pisters, P., 2008, Delirium Cinema or Machines of the Invisible? In: Deleuze and the schizoanalysis of cinema (Patricia MacCormack and Ian Buchanan, eds), Continuum International Publishing Group, London.

Powell, A., 2012, The Daemons of Unplumbed Space: Mixing the Planes in Hellboy. In: Deleuze and Film (David Martin-Jones and William Brown, eds), Edinburgh University Press, Edinburgh.

Powell, A, 2007, Deleuze, Altered States and Film. Edinburgh University Press, Edinburgh.

Powell, A., 2006, Teaching the Gothic. Palgrave Macmillan, New York.

Rodley, C. (ed), 2005, Lynch on Lynch. Farber \& Farber, London.

Royle, N., 2003, The uncanny. Manchester University Press, Manchester.

Savoy, E., 2002, The Rise of American Gothic. In: The Cambridge Companion to Gothic Fiction (Jerrold E. Hogle, ed), Cambridge University Press, New York.

Spoto, D., 1999, The Dark Side of Genius: The Life of Alfred Hitchcock. Da Capo Press, Los Angeles.

Tobe, R., 2003, Both Frightening and Familiar: David Lynch's Twin Peaks and The North American Suburb. In: Visual Culture and Tourism, (David Crouch, ed.), Berg Publications, Oxford.

Williams, D., 1995, Art of Darkness: A Poetics of Gothic. University of Chicago Press, Chicago.

Wood, R., 1989 Hitchcock's Films Revisited, Columbia University Press, New York. 